\title{
Social distancing, social justice, and risk during the COVID-19 pandemic
}

\author{
Diego S. Silva ${ }^{1,2} \cdot$ Maxwell J. Smith ${ }^{3}$ \\ Received: 3 April 2020 / Accepted: 1 June 2020 / Published online: 8 July 2020 \\ (C) The Canadian Public Health Association 2020
}

\begin{abstract}
Social distancing is an important and necessary measure to help arrest the spread of SARS-CoV-2 during the COVID-19 pandemic. However, it does place persons who are socially or politically marginalized, including those who are of lower socio-economic status, at risk of further harms. In other words, marginalized or disadvantaged persons are at risk of both contracting SARS-CoV-2 and the risk of harms that may come about because of the social distancing measures themselves. Finally, a third layer of risk faced by marginalized persons would be the overuse of utility (i.e., maximize the benefit of resource $x$ ) as the primary ethics principle upon which to make allocation decisions, since oftentimes it is resource-intensive to help those in positions of social marginality. This three-fold risk of harm to which marginalized persons are subjected runs counter to the very notion of social justice that underpins public health. Social distancing in a socially just manner requires dialoguing with affected populations and providing social supports to marginalized persons, regardless of the associated costs.
\end{abstract}

\section{Résumé}

La distanciation sociale est importante et nécessaire pour endiguer la propagation du SRAS-Cov-2 durant la pandémie de COVID-19. Elle expose toutefois les personnes socialement ou politiquement marginalisées, dont les personnes de faible statut socioéconomique, à des préjudices supplémentaires. Autrement dit, les personnes marginalisées ou défavorisées sont vulnérables au SRAS-Cov-2 et aux préjudices qui peuvent se manifester en raison des mesures de distanciation sociale. Enfin, les personnes marginalisées sont exposées à un troisième niveau de risque : la surutilisation du principe d'utilité (c.-à-d. maximiser les avantages de la ressource $x$ ) dans la prise des décisions d'allocation des ressources, car il faut souvent beaucoup de ressources pour aider les personnes en marge de la société. Ce triple risque de préjudice auquel sont exposées les personnes marginalisées va à l'encontre de la notion même de justice sociale, qui est la pierre d'assise de la santé publique. Pour être socialement juste, la distanciation sociale nécessite un dialogue avec les populations touchées et l'offre de soutiens sociaux aux personnes marginalisées, indépendamment des coûts associés.

Keywords Ethics $\cdot$ Bioethics $\cdot$ Infectious diseases $\cdot$ Coronavirus $\cdot$ Health policy

Mots-clés Éthique $\cdot$ bioéthique $\cdot$ maladies infectieuses $\cdot$ coronavirus $\cdot$ politique de santé

Diego S. Silva

diego.silva@sydney.edu.au

1 Sydney Health Ethics, Sydney School of Public Health, University of Sydney, Building 1, Level 1, Medical Foundations Building, 92/94 Parramatta Rd, Camperdown, NSW 2050, Australia

2 Marie Bashir Institute for Infectious Diseases and Biosecurity, University of Sydney, Camperdown, Australia

3 School of Health Studies, Faculty of Health Sciences, Western University, Room 222, Labatt Health Sciences Building, London, Ontario N6A 5B9, Canada
Infectious disease pandemics, like COVID-19, do not excuse us from our social justice obligations. As such, social distancing must abide by the principles and values of social justice.

The use of social distancing measures has proven essential to curb the spread of the COVID-19 pandemic and will continue to be an important measure in the months to come. Yet instituting these measures in a fair and just manner requires the provision of social supports for persons who are socially and politically marginalized or disadvantaged, e.g., persons who are homeless or living in congregate settings, migrant workers, prisoners, and persons of lower socio-economic 
status. While we cannot necessarily control the risk factors associated with the physical COVID-19 virus, we can and must carefully consider the risks associated with social distancing and other restrictive public health measures. The fair distribution of the benefits and burdens of these measuresi.e., one of the central concerns of social justice - is directly related to the imposition of risk among these populations, which is a growing area of concern among bioethicists.

Social distancing subjects many marginalized persons to three overlapping and compounding forms of risk: (1) the biological risks associated with the COVID-19 virus (SARSCoV-2), (2) the risks associated with social distancing, and (3) the risks that accompany the often uncritical reliance on basing public health decision-making during pandemics on a principle that compels us to produce the greatest good for the greatest number of people (i.e., the principle of utility). The social distancing measures used around the world must immediately seek to minimize these risks, lest the greatest burdens fall upon those already least advantaged.

\section{The multiplicity of risks of social distancing measures}

To begin, persons who are disadvantaged might be in grave physical danger of succumbing to SARS-CoV-2 due to an inability to protect themselves. Public health measures recommended or ordered during the COVID-19 pandemic often assume people are housed (e.g., "stay at home"), can maintain a certain distance with others, and have access to running water and soap (e.g., "wash your hands"), none of which are typically possible for those sleeping rough or living in congregate settings (e.g., shelters and refugee camps) (Tsai and Wilson 2020). Moreover, the immune systems of such persons may not be at full or normal capacity due to the lack of nutritious foods. Other marginalized populations will likely face other risks: migrants and refugees often have little-to-no access to primary healthcare or may be in a country illegally, which may result in their not seeking care for COVID-19 in a timely manner. In the case of prisoners, it may be impossible to isolate safely at all. Thus, although the current data on the matter are provisional (CDC 2020), there are reasons to believe that many marginalized persons are at greater risk of getting infected with SARS-CoV-2, developing COVID-19, and suffering more severe forms of illness than those in the general population due to underlying social and economic conditions.

In addition to potentially worse physical outcomes, social distancing itself risks negatively impacting marginalized persons in a number of ways. As a means of stemming the rate of infection related to COVID-19, we fully and unequivocally support social distancing initiatives as an effective and ethical measure. For the general population, the potential ill effects of social distancing are relatively well known and have been discussed regularly in the media, including the feeling of social isolation and the potential lack of physical movement from being indoors for longer than normal. Persons who are homeless, however, face additional risks related to social distancing. For example, they may not be able to access social services provided by governments or charities, or may be unable to go to shelters if they are closed. In cold-weather environments, this may also require either being subjected to the risk of infection by continuing to sleep in congregate settings, or risk the elements of winter, potentially with its own set of dire consequences (e.g., freezing to death). Another example would be the potential deterioration of migrant workers' mental health, e.g., greater rates of depression during extensive periods of isolation, since mental illnesses exist at higher rates within these populations than in the general population (Liem et al. 2020). Migrant workers may be asked to leave their dwellings or might lose their employment due to the current economic downturn, and thus become homeless, then becoming subject to the risks associated with homelessness. Thus, there exists an extensive list of challenges that arise due to social distancing that disproportionately risks the well-being of marginalized persons, e.g., increased drug use, increased rates of mental illnesses, increased rates of domestic violence (Usher et al. 2020).

Finally, there is a tendency during emergencies, like pandemics, to resort to overly simplistic utility calculations in public health (e.g., maximizing best outcomes with little regard for their distribution between population groups) (Veatch 2005; Kirkwood 2017; Smith et al. 2019). In these contexts, saving the most lives possible seems to trump other ethics considerations like social justice concerns for the most disadvantaged. And while there are some instances when such decisions are perhaps justified (e.g., allocation of ventilators if they are scarce), even during emergencies we ought to include considerations in addition to mere utility (e.g., need or equity) to avoid further disadvantaging the already disadvantaged (Silva et al. 2013).

Therefore, as noted at the outset, many marginalized persons are subject to three forms of risk that compound during pandemics: the medical risks associated with COVID-19, the risks associated with social distancing, and the risks associated with an overreliance on the principle of utility during pandemics. Only the first of those three risks are shared by all members of a society, while the third risk may endanger other potentially vulnerable persons (e.g., the elderly with regard to the allocation of scarce medical resources). This requires special consideration for disadvantaged populations in the use of social distancing measures.

Social justice, then, requires taking into account not only the harms that occur in the context of addressing COVID-19 but also the risks to which people are subjected in the course of addressing the pandemic. Social justice requires not only 
the fair distribution of benefits and burdens but also the fair distribution of the risks of burdens (Wolff and De-Shalit, 2007). Public health, it has been said, holds social justice as its "core value" (Gostin and Powers 2006). It follows that public health ought to care about social justice as it relates to COVID-19. Therein lies the rub: if questions about the just distribution of benefits and burden matters to public health and global health, then we should also care about the just distribution of the risks associated with COVID-19 in relation to the measures implemented to arrest its spread. What we do not want to do is exacerbate inequalities, especially in those instances where there is no plausible justification to do so.

\section{Policy implications and recommendations}

The implications for public health policy are clear: taking into account the risks associated with social distancing and marginalized populations is not a "nice to have" but a "must have" consideration in COVID-19-related policies and procedures.

Concretely, governments must quickly dialogue with advocates and healthcare practitioners who work with disadvantaged populations, including persons who are homeless, migrant populations, and prisoners (McDonald 2020). These communities are in the best position to provide relevant and practicable suggestions, including where and how best to allocate resources. They also have the "know how" to navigate the various health and social systems relevant to aforementioned groups. Those working with disadvantaged populations who are not healthcare workers should still be fitted for personal protective equipment, provided with the requisite education for how to work safely during the pandemic, and be given the justification for the various public health measures enacted, including that of social distancing.

Second, persons living in congregate settings, the homeless, or the precariously housed should have access to free and safe shelter whenever possible. Although persons who require isolation should take precedence, motels and hotels that are not being occupied should be used to facilitate social distancing of marginalized persons. Motel and hotel owners should be encouraged to work with city and other government officials to facilitate occupancy. Although it might seem extreme, it may be necessary to commandeer hotels and motels for the purposes of slowing down the spread of COVID-19. (As the saying goes, desperate times call for desperate measures.) Toronto, Canada, has already begun to go down this path by housing homeless persons in hotels that are not presently being used (Canadian Press 2020). Finally, persons must be provided with the means of maintaining social distancing in a safe and sound manner.

The cost of providing such social support to those most marginalized will undoubtedly be high. However, if governments and societies can find the billions of dollars necessary to help a multitude of industries overcome the economic losses associated with COVID-19, we believe that it should likewise be possible to allocate money to promote social justice when implementing social distancing. Doing so helps those who are disadvantaged and of lower socio-economic status stay safe and as healthy as possible.

\section{Compliance with ethical standards}

Conflict of interest The authors declare that they have no conflict of interest.

\section{References}

Canadian Press. (2020). City of Toronto acquires hotels, rental buildings for homeless in response to coronavirus. CityNews. Available at: https://toronto.citynews.ca/2020/03/29/toronto-homelesscoronavirus-hotels/. Accessed 3 Apr 2020.

Centers for Disease Control. (2020). COVID-19 in racial and ethnic minority groups. CDC.gov. Available at: https://www.cdc.gov/ coronavirus/2019-ncov/need-extra-precautions/racial-ethnicminorities.html. Accessed 3 Apr 2020.

Gostin, L., \& Powers, M. (2006). What does social justice require for the public's health? Public health ethics and policy imperatives. Health Affairs, 25(4), 1053-1060.

Kirkwood, K. (2017). In the name of the greater good? Emerging Health Threats Journal. https://doi.org/10.3402/ehtj.v2i0.7092.

Liem, A., Wang, C., Wariyanti, Y., et al. (2020). The neglected health of international migrant workers in the COVID-19 epidemic. Lancet Psychiatry. https://doi.org/10.1016/S2215-0366(20)30076-6.

McDonald, S. (2020). COVID-19: what state and local leaders can do for homeless populations. National Alliance to End Homelessness [notfor-profit organization], Washington, DC. Available at: https:// endhomelessness.org/covid-19-what-state-and-local-leaders-cando-for-homeless-populations/.

Silva, D. S., Smith, M. J., \& Upshur, R. E. G. (2013). Disadvantaging the disadvantaged: when public health policies and practices negatively affect marginalized populations. Canadian Journal of Public Health, 104(5), e410-e412.

Smith, M. J., Thompson, A., \& Upshur, R. E. G. (2019). Public health as social justice? A qualitative study of public health policy-makers' perspectives. Social Justice Research, 32(3), 384-402.

Tsai, J., \& Wilson, M. (2020). COVID-19: a potential public health problem for homeless populations. The Lancet Public Health. https://doi. org/10.1016/S2468-2667(20)30053-0.

Usher, K., Bhullar, N., Durkin, J., Gyamfi, N., \& Jackson, D. (2020). Family violence and COVID-19: increased vulnerability and reduced options for support. International Journal of Mental Health Nursing. https://doi.org/10.1111/inm.12735.

Veatch, R. (2005). Disaster preparedness and triage: justice and the common good. The Mount Sinai Journal of Medicine, 72(4), 236-241.

Wolff, J., \& De-Shalit, A. (2007). Disadvantage. New York: Oxford University Press.

Publisher's note Springer Nature remains neutral with regard to jurisdictional claims in published maps and institutional affiliations. 